\title{
A CONSTRUÇÃO LÓGICA DO "ESTILO NEWTONIANO"
}

\section{The logical construction of the "Newtonian Style"}

\author{
Raquel Anna Sapunaru ${ }^{1}$
}

\begin{abstract}
Resumo: O historiador da ciência Isaac Bernard Cohen batizou o novo método de "fazer ciência", criado por Isaac Newton, de "estilo newtoniano". Segundo Cohen, o cerne do "estilo newtoniano"seria a adaptação sucessiva das "construções mentais" - matemáticas - às comparações com a natureza e haveria dinâmica direta entre as "construções mentais" - matemáticas - e os sistemas físicos. Uma das principais características do "estilo newtoniano", portanto, seria primeiramente a matemática e, posteriormente, uma série de experimentos - e não o contrário. Brilhantemente, enquanto escrevia os Princípios Matemáticos de Filosofia Natural, Newton teria concluído que descrever o movimento de planetas e satélites, ou o movimento em geral, com precisão absoluta era imensamente mais complicado do que seus contemporâneos e antecessores poderiam ter pensado. A solução encontrada por ele foi, partindo de simples casos idealizados, passar progressivamente para casos mais complicados, também idealizados, e depois percorrer o caminho oposto, isto é: pelo desmembramento dos casos mais complicados provar os mais simples, embora sempre em direção à verdade.
\end{abstract}

Palavras-chave: Newton. Método. Matemática. "Estilo newtoniano”.

\begin{abstract}
The science historian, Isaac Bernard Cohen named the new method of "making science" created by Isaac Newton by the name of "newtonian style". The central point of this "newtonian style", according to the definition of Cohen himself is the successive adaptation from "mental constructions" - to mathematical - to comparisons with nature. This means that, according to Cohen, a direct dynamic between "mental constructions" - mathematical - and physical systems should exist. For this reason, one of the most important characteristics of the "newtonian style" would be, first, mathematics and, afterwards, a series of experiments - and not the other way round. Newton would have brilliantly concluded, while writing the "Mathematical Principles of Natural Philosophy", that, to describe with absolute precision the movement of planets and satellites, or movement in general, was immensely more complicated than his contemporaries and ancestors would have thought. In this way, the solution found by Newton was to start from simple idealized cases, passing progressively to other also idealized but more complicated cases and finally to go to the opposite way, that means, to prove the most simple cases through divisions of more complicated cases, although always in the direction of truth.
\end{abstract}

Key words: Newton. Method. Mathematics. "Newtonian style".

${ }^{1}$ Doutoranda em Filosofia; professora, Centro de Educação a Distância do Estado do Rio de Janeiro (CEDERJ), Universidade Candido Mendes - Centro de Pós-Graduação e Extensão (UCAM-CPGE), Instituto Augusto Compte de Altos Estudos (IACAE). Rio de Janeiro, RJ. <raquel.anna@ig.com.br>

Rua Rainha Guilhermina, 117/906

Leblon - Rio de Janeiro, RJ

$22.441-120$ 
O historiador da ciência Isaac Bernard Cohen batizou o novo método de "fazer ciência", criado por Isaac Newton, de "estilo newtoniano". O cerne do "estilo newtoniano", segundo o próprio Cohen em O Método de Newton e o Estilo de Newton, seria a adaptação sucessiva das "construções mentais" - matemáticas - às comparações com a natureza, isto é, do ponto de vista de Cohen (2002, p. 164) haveria uma dinâmica direta entre as "construções mentais" - matemáticas - e os sistemas físicos. Portanto, uma das principais características do "estilo newtoniano" seria primeiramente a matemática e, posteriormente, uma série de experimentos - e não o contrário.

Não obstante, uma visão mais técnica do "estilo newtoniano" foi dada por George Smith no artigo A Metodologia do Principia (SMITH, 2002). Para ele, a expressão if-quam proximethen-quam proxime - se-quanto mais próximo "chegarmos do fenômeno"- então-quanto mais próxima "será a caracterização das leis que regem estes fenômenos" - derivada do termo if-then - seria a base lógica do "estilo newtoniano". Brilhantemente, enquanto escrevia os Princípios Matemáticos de Filosofia Natural, Newton teria concluído que descrever o movimento de planetas e satélites, ou o movimento em geral, com precisão absoluta, era imensamente mais complicado do que seus contemporâneos e antecessores poderiam pensar ou ter pensado. Assim, a solução encontrada por Newton foi, partindo de simples casos idealizados, passar progressivamente para outros casos mais complicados, também idealizados, e depois percorrer o caminho oposto, isto é: pelo desmembramento dos casos mais complicados provar os mais simples, embora sempre em direção à verdade.

Smith (2001) acredita que Newton teve uma extraordinária visão do caminho pelo qual uma seqüência de recursos matemáticos derivados da proposição if-quam proxime-thenquam proxime permitiria que o mundo empírico, principalmente o fenômeno do movimento planetário, respondesse, primeiramente, mesmo que por aproximação, a questões sobre a força que governava esse movimento e, depois, a questões relativas ao movimento em geral, deixadas em aberto por René Descartes e seus seguidores.

Num primeiro momento, os Princípios Matemáticos de Filosofia Natural poderiam dar a impressão de estar trilhando os mesmos caminhos lógicos que as obras de Galileo Galilei e Cristiaan Huygens, visto Newton, provavelmente, ser profundo conhecedor das mesmas. Porém, para Smith (2002) a obra de Newton diferiu das de Galileo e Huygens em dois aspectos: 1) enquanto todas as demonstrações das proposições empíricas dos Livros I e II dos Principios Matemáticos de Filosofia Natural eram da forma if-then - se-então - e if-and-only-if se-e-somente-se - bases da if-quam proxime-then-quam proxime - as demonstrações das proposições empíricas das obras de Galileo e Huygens eram da forma when-then - quando-então; e 2) enquanto Galileo apresentou uma teoria matemática para o movimento uniformemente acelerado e Huygens estendeu a teoria galileana para as trajetórias curvilíneas e para o movimento circular uniforme, Newton não apresentou uma teoria matemática para um único aspecto da Física, mas, sim, para todo o tratamento que envolvia as forças e leis que as regiam.

Smith (2002, p. 142) classificou a primeira diferença de "engenhosa", visto que, logicamente falando, if-then e when-then significariam a mesma coisa. Contudo, numa visão empírica, a forma lógica when-then significaria que os antecedentes da proposição empírica descreveriam uma "situação experimental", enquanto o conseqüente descreveria uma predição daquilo que iria ocorrer quando aquela situação descrita no antecedente se consumasse. Já a forma lógica if-then equivaleria a "permissões" para inferir ou "navegar" de movimento para força, 
de força para movimento e das "macro-forças" para as "micro-forças" que as comporiam. Entendemos por macro-forças as "forças de ação contínua" como a "força centrípeta" e como "micro-forças" as "forças de percussão" que, apesar de agirem num tempo infinitesimal, somadas comporiam uma "força de ação" contínua. Por outro lado, acreditamos, também, que a proposição empírica when-then remontaria a uma precisão fenomênica que não existiria em todos os instantes, enquanto as proposições empíricas if-then e if-and-only-if remontariam a uma imprecisão fenomênica matematicamente tratável.

Assim, para Galileo e Huygens, o importante seria caracterizar um fenômeno físico quando este se manifestasse e a visão de Newton estava voltada para a interação dos fenômenos com as forças da natureza - seu principal objeto de estudo. Baseado nessa conclusão, Smith afirmou que:

Newton indica [...] no Prefácio da primeira edição [do Principia] [que], o objetivo das teorias matemáticas dos Livros 1 e 2 é primeiro estabelecer o significado para as conclusões inferidas dos fenômenos do movimento sobre as forças e então demonstrar, mais adiante, o fenômeno destas conclusões sobre as forças. Nas mãos de Newton, força é flagrantemente uma quantidade teórica. O principal problema das teorias matemáticas de Newton é achar caminhos [válidos] para caracterizar essas forças. (SMITH, 2002, p. 143)

A segunda diferença estava mais ligada ao escopo das teorias em si, visto que Galileo e Huygens limitaram-se a aspectos físicos particulares de suas teorias, enquanto Newton abrangeu toda cinemática, baseado nos resultados obtidos pelo próprio Galileo e pela mecânica racional por ele criada. Nas palavras de Smith:

O escopo genérico dessas [...] teorias não é simplesmente o caso de Newton mostrar sua habilidade matemática, como às vezes é sugerido. As teorias necessitam ser genéricas a fim de permiti-lo estabelecer conclusões fortes sobre as forças [derivadas] dos fenômenos dos movimentos, conclusões que excluem afirmações potencialmente competidoras. (SMITH, 2002, p. 144)

De acordo com Smith (2002), a proposição if-quam proxime-then-quam proxime tornouse a base lógica do "estilo newtoniano". Por meio dela, Newton escapou das complexidades de estudar a natureza em si, conforme ela se apresenta. O filósofo partiu de uma versão idealizada da natureza - versão aproximada - na qual algumas leis descritivas das posições e velocidades observadas, Leis de Kepler ${ }^{2}$, aplicavam-se com perfeição incomparável.

\footnotetext{
${ }^{2}$ Primeira Lei ou Lei das Órbitas: os planetas descrevem órbitas elípticas em torno do Sol, que ocupa um dos focos da elipse descrita; Segunda Lei ou Lei das Áreas: o segmento imaginário que une o centro do Sol e o centro do planeta varre áreas proporcionais aos intervalos de tempo dos percursos; Terceira Lei ou Lei dos Períodos: o quadrado do período de revolução de cada planeta é proporcional ao cubo do raio médio respectiva órbita. $\mathbf{T}^{2}=\mathbf{k} \mathbf{R}^{3}$, ou melhor, $\mathbf{k}=\mathbf{T}^{2} / \mathbf{R}^{3}$.
} 
Logo após esta etapa, baseando-se em princípios e leis deduzidos da combinação do constructo com a observação natural, Newton passou para novos constructos, princípios e leis, agora mais gerais. Desta forma, passo a passo, chegou finalmente à Lei da Gravitação Universal. Para Smith:

\begin{abstract}
Newton tinha concluído que as leis de Kepler podem ser, no melhor dos casos, mais verdadeiras só quam proxime [quanto mais próxima] dos planetas e seus satélites, não por causa da imprecisão da observação, mas porque os verdadeiros movimentos são imensamente mais complicados que Kepler ou outro [cientista] pudesse esperar entender de tais regras. (SMITH, 2002, p. 153-154)
\end{abstract}

Esse tipo de tratamento dado por Newton a fenômenos naturais poderia pressupor uma certa utilização de estratagemas ad hoc, devido ao massivo uso de constructos matemáticos. No entanto, Smith (2002) acredita que Newton queria, de fato, evitar tais estratagemas, principalmente com relação à questão das forças ligadas à Lei da Gravitação Universal. Isso porque ela não poderia ser verificável da mesma forma que, eventualmente, outras leis da Física, pois não haveria como investigar se todas as partículas mecânicas do universo realmente se atraem, conforme dito em seu enunciado.

Em outro artigo, intitulado $O$ estilo newtoniano no Livro II do Principia, Smith analisa particularmente o "estilo newtoniano" do Livro II comparando-o aos Livros I e III. Segundo Smith (2001), aplicada aos Livros I e III a descrição dada por Cohen para o "estilo newtoniano" enfatizava o modo pelo qual as teorias matemáticas utilizadas pelo filósofo eram submetidas a uma seqüência de aproximações. Seqüência que, como vimos anteriormente, obedecia à forma lógica if-quam proxime-then-quam proxime. Newton começou sua narrativa nos Princípios Matemáticos de Filosofia Natural idealizando um único corpo; mais adiante introduziu um segundo corpo e, finalmente, o terceiro corpo, criando um sistema generalizado.

Em total acordo com a teoria de Cohen, para Smith (2001), o importante seria notar que cada sucessiva idealização do sistema prolongava a idealização do sistema antecedente, abandonando a hipótese matemática anterior por outra mais complexa. Nesse contexto, a hipótese defendida por Smith (2002), na qual Newton teria uma visão empírica da ciência que progrediria por meio de sucessivas aproximações dos modelos matemáticos, parece bastante coerente e corrobora o modelo de Fernandes (1985), baseado na análise dos pensamentos de Immanuel Kant e Karl Popper. Para esse comentador, toda idealização - matemática ou não - pressuporia, ou melhor, exigiria a existência de hipóteses implícitas. No caso de Newton, apesar da visão empírica e do uso intenso dos modelos matemáticos, ele já teria em mente a solução do problema que se propôs por meio de idealizações.

Complementando a visão do "estilo newtoniano" nos Princípios Matemáticos de Filosofia Natural, Smith (2001) afirmou que, devido ao mundo empírico tratado no Livro II possuir características diferentes do tratado nos Livros I e III (o Livro II ficou conhecido por tratar de problemas relacionados à hidrostática), esse volume foi capaz de dar um "brilho" especial ao "estilo newtoniano" de Cohen. Para muitos, o Livro II parecia uma mera digressão do Livro I, que apontava claramente para o Livro III, a menos da crítica ao vórtice cartesiano. Porém, para Smith (2001), Newton considerava o Livro II como parte do mesmo projeto 
que o levou a escrever os Livros I e III, isto é: matematizar de vez a natureza. Mesmo concordando inteiramente com Cohen (2002) sobre as particularidades que envolvem o "estilo newtoniano" nos Livros I e III, nos dois artigos citados, usando seus próprios termos, Smith procurou "embelezar" ainda mais este estilo com duas novas análises.

Na primeira, partiu do seguinte princípio: “[...] até a mais simples das idealizações [feitas por Newton] era mais do que somente um passo matemático para o próximo [estágio]." (SMITH, 2001, p. 250), como já havia afirmado Cohen (2002). De acordo com Smith (2001), Newton teria usado idealizações até mesmo para extrair conclusões dos fenômenos observados pelos astrônomos de sua época, descritos no Livro III e, freqüentemente, estas conclusões tomariam a forma de "medidas de quantidades inferidas". Por exemplo, utilizando o modelo idealizado de um único corpo dos fenômenos observados, Newton (1999) inferiu: 1) a massa do Sol; 2) a massa de Júpiter; 3) a massa de Saturno; e 4) o valor do expoente de $\mathbf{r}$ na Lei da Gravitação Universal ${ }^{3}$. Para Smith, teriam sido a estabilidade da matemática e do modelo idealizado, a concordância mútua entre ambos e a precisão das medidas provenientes dos dados empíricos fornecidos pelos astrônomos os responsáveis pelo sucesso da nova Física de Newton: "Independentemente do tipo de inferência que ele estava extraindo [da natureza], Newton (1999) estava usando a idealização como instrumento de condução de evidências" (SMITH, 2001, p. 250).

Na segunda análise, Smith (2001) defendeu a hipótese de que não seria qualquer tipo de aproximação que permitiria uma investigação empírica de sucesso, pois, como se pode prever, poderiam haver "discrepâncias residuais" deixadas entre uma e outra idealização mais refinada. Em termos newtonianos, algumas dessas "discrepâncias residuais" deveriam equivaler a fenômenos dos quais conclusões pudesse ser extraídas, especialmente conclusões que estabelecessem a próxima idealização na seqüência de aproximações sucessivas. Por exemplo, as desigualdades lunares - a variação da gravidade lunar de acordo com a latitude e a discrepância entre as variações e a idealização da densidade uniforme da Terra - forneceriam a maior evidência de que as "discrepâncias residuais" poderiam se tornar fenômenos. Para Smith, Newton extraiu conclusões surpreendentes de algumas dessas discrepâncias, porém, deixou outras de lado, talvez para serem exploradas em momento mais oportuno.

Portanto, na Física de Newton a seqüência de idealizações era: 1) a principal responsável pelas sucessivas aproximações; e 2) obrigatoriamente empírica. Esta seqüência de idealizações solicitava um tipo especial de aproximação, visto que não seria qualquer uma capaz de produzir uma "discrepância residual" quando comparada à observação que poderia, finalmente, estar disposta em evidências para a próxima aproximação. Nas palavras de Smith:

Quando eu falo do 'Estilo Newtoniano', então, eu estou me referindo a uma aproximação envolvendo uma seqüência de aproximações de idealizações, [onde] cada qual é usada para extrair conclusões do fe-

\footnotetext{
${ }^{3}$ A Lei da Gravitação Universal, representada pela "força centrípeta”, em sua forma contemporânea é: $\mathbf{F}=\mathbf{G}$ $\mathrm{m}_{1} \cdot \mathrm{m}_{2} / \mathrm{r}^{2}$
} 
Sapunaru, R. A.

nômeno, e que juntas abrangem sucessivas aproximações na qual discrepâncias residuais entre a teoria e a observação em cada estágio providencia evidencias de base para o próximo estágio. (SMITH, 2001, p. 251)

Destarte, de forma bastante sintética e baseada nos comentários de Cohen (2002) e Smith (2001), esse "estilo newtoniano" consistiria em tratar um sistema físico de modo idealizado - matemática, modelos, aproximações - utilizando-se, primeiro, a indução e, depois, a dedução, confrontando-o com a realidade da natureza - mediante experimentos reais - e, finalmente, ajustando-o em direção à verdade. David Gregory, contemporâneo e admirador de Newton, parece ter compreendido com clareza inigualável o modo com que o filósofo tratava os problemas que a natureza a ele se desvelava e revelou, baseado em sua própria análise dos Princípios Matemáticos de Filosofia Natural, que:

A melhor maneira de superar um problema difícil é resolvê-lo em alguns casos particulares fáceis. Isso esclarece muito a solução geral. É dessa maneira que Sir Isaac Newton afirma ter superado as [suas] maiores dificuldades. (GREGORY, 2002, p. 150)

Mesmo assim, Cohen afirma que Newton teria escrito os Princípios Matemáticos de Filosofia Natural não com intenção de inaugurar uma nova ciência baseada em um novo método, mas, somente no intuito de encontrar a "forma geométrica" da órbita planetária produzida por uma força que variasse com o inverso do quadrado da distância. Segundo este historiador, Newton, profundo conhecedor do pensamento de Johannes Kepler, já sabia que a "forma geométrica" da órbita planetária era elíptica, fato que poderia levantar dúvidas sobre qual a real definição de "indução" referida por Cohen (2002) e Smith (2002).

Por outro lado, em seus Estudos Newtonianos Koyré (1985) afirmou que se nos basearmos nas palavras de Newton, quando disse que:

[...] não invento hipóteses. Portanto tudo o que não é deduzido dos fenômenos deve ser chamado de hipótese; e as hipóteses, se metafísicas ou físicas, baseadas em qualidades ocultas, ou mecânicas, não têm lugar na filosofia experimental. Nessa filosofia experimental proposições são deduzidas [inferidas] de fenômenos e [depois] generalizadas por indução (NEWTON, 1999, p. 943),

seria deveras fácil atribuir à Física de Newton um caráter totalmente positivista. Isto significaria dizer que Newton teria se utilizado largamente do método indutivo na formulação de sua Física e que o uso do método hipotético-dedutivo teria sido apenas uma conseqüência proveniente do emprego habitual da geometria euclidiana, base de seu método, como sua principal ferramenta matemática.

Por esta razão, estaria então justificada a presença do método hipotético-dedutivo ao longo das proposições, lemas e problemas dos Princípios Matemáticos de Filosofia Natural. Porém, como já vimos, não podemos ignorar que, para Newton, a relação entre a geometria 
euclidiana e a Física ultrapassaria o mero uso de uma ferramenta matemática. Assim, devido a essas contradições a respeito do método utilizado por Newton, Koyré (1985) argumentou ser muito difícil saber o que exatamente Newton estava querendo dizer quando proferiu aquela que seria sua mais famosa frase: “[...] não invento hipóteses".

Em seu artigo Teorias do Método Científico de Platão a Mach, Larry Laudan fez uma curiosa observação sobre a famosa frase: "É certamente irônico [...] que autores sobre a teoria do método científico de Newton têm algumas vezes devotado mais atenção para o que ele queria dizer por 'invento' do que ele queria dizer por 'hipóteses"' (LAUDAN, 1968, p. 8). Em carta a Cotes datada de 28 de março de 1713, o próprio Newton esclareceria o uso do termo "hipótese" em seus escritos:

[...] a dificuldade que o senhor menciona haver nas palavras 'Et cum Attractio omnis mutua sit [E uma vez que toda atração é mútua] é eliminada ao considerarmos que, assim como, na geometria, a palavra hipótese não é tomada num sentido tão amplo que inclua os axiomas e os postulados, também na filosofia experimental ela não deve ser tomada em sentido tão amplo a ponto de incluir os princípios ou axiomas primordiais que denomino de leis do movimento. Esses princípios são deduzidos dos fenômenos e generalizados por indução, o que é a mais alta comprovação que uma proposição pode ter nessa filosofia. E a palavra 'hipótese' é usada por mim, [...], apenas para expressar uma proposição que não seja um fenômeno nem seja deduzida de qualquer fenômeno, mas presumida ou pressuposta, sem nenhuma comprovação experimental. (NEWTON, 2002, p. 155)

De acordo com Laudan (1968), apesar de Newton ter vários escritos sobre seu método, nenhum deles deixou claro o que ele realmente utilizou como "método científico", principalmente na elaboração dos Princípios Matemáticos de Filosofia Natural. Para este autor, o vocabulário utilizado por Newton nas questões relacionadas a seu método de investigação "foi vago e inconsistentemente aplicado". Segundo o epistemólogo, Newton não deixou claro o que quis dizer com "não invento hipóteses" e o que seria "deduzir" ou "induzir" leis de fenômenos naturais. Estes conceitos ora significavam uma coisa, ora outra. Neste ponto, Laudan pareceu concordar inteiramente com Koyrè (1985) que, ao analisar o método utilizado por Newton, também se mostrou titubeante com relação aos mesmos termos - "não invento hipóteses", "deduzir" ou "induzir" leis de fenômenos naturais, entre outros - ligados à metodologia dos escritos de Newton.

A análise de Laudan mostrou, também, que o historiador da ciência, Richard Blake, via Newton como o fundador do método hipotético-dedutivo enquanto um outro historiador da ciência, W. Whewell, pensava que o grande erro de Newton havia sido a "denúncia prematura de todas as suas hipóteses" (1968, p. 23-24). Mesmo titubeante com relação a certos termos ligados à metodologia newtoniana, Koyré (1985) finalmente concluiu que os arroubos indutivistas de Newton seriam meras necessidades locais, isto é, caso o filósofo tivesse mesmo se utilizado desse método, o teria feito única e exclusivamente para resolver questões pouco relevantes em sua Física. Apesar de admitir que às vezes teria ficado confuso 
Sapunaru, R. A.

com relação às palavras proferidas por Newton sobre seu método, este historiador e filósofo da ciência não admitia que Newton pudesse cometer tal "falha metodológica".

Particularmente sobre a questão das hipóteses newtonianas, talvez Newton não fosse totalmente contrário à sua utilização, pois senão nem teria dito que "não as inventava" e nem seria apontado por historiadores e filósofos da Física como um dos fundadores da Física Experimental. É provável que acreditasse que as hipóteses seriam fontes inesgotáveis de experimentos e, sendo assim, a expressão "não invento hipóteses" estaria mais associada à impossibilidade de sua comprovação experimentalmente, como fora o caso do vórtice cartesiano. Nas palavras escritas por Newton a Oldenburg, em 1672:

Pois o melhor e mais seguro método de filosofar parece consistir, primeiramente, em investigar com diligência as propriedades das coisas e estabelecer essas propriedades através de experimentos, e, depois, em proceder a hipóteses para a explicação das coisas em si. (NEWTON, 2002, p. 156)

No mesmo ano, em outra carta a Oldenburg, Newton completou:

O senhor [Oldenburg] sabe que o método adequado para investigar as propriedades das coisas é deduzi-las de experimentos. E eu lhe disse que a teoria que propus foi-me evidenciada não por inferência de que é assim porque não pode ser de outra maneira, ou seja, não por deduzila unicamente de uma refutação das suposições contrárias, mas por derivá-la de experimentos que levaram a conclusões positivas e diretas. (NEWTON, 2002, p. 157)

Face ao que foi discutido, concluímos que, assim como Descartes e Francis Bacon, Newton deu enorme atenção ao método utilizado na elaboração de sua Física, ainda que o método newtoniano seja essencialmente diferente dos outros. Vale lembrar que: 1) para muitos comentadores, Newton seria o sucessor de Bacon na linhagem dos filósofos empiricistas; e 2) o novo método da Física moderna, chamado por Bacon de Novum Organum era: a) predominantemente experimental; b) baseado na indução; c) quantitativo; e d) não somente observacional. O objetivo maior deste novo método era, sem sombra de dúvidas, levar os filósofos da natureza a formularem leis e princípios baseados principalmente na matemática. Deste modo, para Cohen:

O objetivo newtoniano nos Principia foi mostrar que os 'princípios matemáticos' ou abstratos dos dois primeiros livros podiam ser aplicados ao mundo revelado pelos fenômenos, tarefa a que ele se dedicou no terceiro livro. Fazer isso, depois de Galileu, Kepler, Descartes e Huygens, não era revolucionário em si, embora o alcance dos Principia e o grau de aplicação confirmada bem possam ser designados dessa maneira e, portanto, constituir uma parte integrante da Revolução Newtoniana na ciência. (COHEN, 2002, p. 165) 
Contudo, o que Cohen chamou de "Revolução Newtoniana" não abrangeu somente os Princípios Matemáticos de Filosofia Natural. Para o comentador, teria sido na Ótica que Newton revelou sua verdadeira concepção do método científico experimental. Na Questão 31 dessa obra, Newton declarou sua concepção metodológica de maneira mais precisa, a saber:

Tal como na matemática, também na Filosofia Natural a investigação das coisas difíceis pelo método de análise deve sempre preceder o método da composição [síntese]. Essa análise consiste em fazer experimentos e observações e deles extrair conclusões gerais, através da indução, e em não aceitar nenhuma objeção contra as conclusões senão as que forem extraídas de experimentos ou de outras verdades seguras. Pois as hipóteses não devem ser levadas em consideração na filosofia experimental. E, conquanto a argumentação advinda de experimentos e observações, através da indução, não constitua uma demonstração das conclusões gerais, ela é, ainda assim, a melhor forma de argumentação admitida pela natureza das coisas, e pode ser considerada tão mais sólida quanto mais geral for a indução. E, se não ocorrer nenhuma exceção a partir dos fenômenos, a conclusão pode ser afirmada em termos gerais. Mas se, em algum momento posterior, ocorrer qualquer exceção proveniente dos experimentos, a conclusão poderá começar a ser pronunciada com as exceções constatadas. Através desse modo de análise podemos proceder dos compostos para os ingredientes, e dos movimentos para as forças que os produzem, e, em geral, dos efeitos para suas causas, e das causas particulares para outras mais gerais, até que a argumentação termine no mais geral. Esse é o método de análise. [A síntese consiste em presumir descobertas pelas causas, e estabelecidos os princípios, através deles, explicar os fenômenos daí provenientes e demonstrar as explicações]. (NEWTON, 2002, p. 151)

Segundo a análise de Cohen (2002), constatamos que Newton seguiu rigorosamente o roteiro descrito por ele mesmo. Assim, o método utilizado na elaboração da Ótica e dos Princípios Matemáticos de Filosofia Natural não poderia sugerir algo diferente. Posteriormente, outros comentadores corroboraram a posição de Cohen e afirmaram, com exemplos mais concretos, que Newton de fato seguira indiscriminadamente sua própria metodologia, utilizando e alternando os conceitos de "análise da Filosofia Natural" com o de "análise matemática", conforme sua necessidade.

Como vimos anteriormente, Koyré (1985) parece discordar desta posição, ao diferenciar os métodos de "análise" e "síntese" da matemática e seus homônimos da Filosofia Natural. Lembramos que a "análise" corresponderia à dedução e a "síntese", à “indução". Por exemplo, de acordo com Bruce Brackenridge (2001), em seu artigo A Dinâmica Madura de Newton, o método básico de análise de Newton nos Princípios Matemáticos de Filosofia Natural poderia ser agrupado sob três "sub-métodos matemáticos" gerais, a saber: a) o método poligonal; b) o método parabólico; e c) o método da curvatura. Estes "sub-métodos matemáti- 
cos" tinham como objetivo provar que uma força de impulso $\mathbf{F}$ direcionada para o centro de um círculo agiria em cada "pedaço infinitesimal" desse círculo. Exemplos semelhantes também seriam encontrados na Ótica. Por sua vez, em Os Experimentos de Newton na Difração, após uma longa digressão sobre a supressão das "franjas" Alan Shapiro concluiu que:

A metodologia de Newton o compeliu a suprimir seu modelo [de propagação linear dos raios de luz e das "franjas"], porque era uma hipótese imposta sobre as observações e não a partir delas. Ele acreditava que hipóteses ou conjecturas não poderiam ser misturadas com a parte mais assertiva da ciência, o fenômeno ou princípio derivado do fenômeno. Tal coisa comprometeria a certeza dada pela ciência. (SHAPIRO, 2001, p. 63)

De forma incontestável, Fernandes (1985) explicou a posição de Newton utilizando argumentos históricos, agregando as posições de Brackenridge e Shapiro à de Cohen:

Acreditava-se normalmente que análise científica de conceitos empíricos sobre suas propriedades fosse possível, muito pelo sentido análogo no qual é possível desmontar uma máquina, ou dissecar um animal. E a síntese científica dos pensamentos era normalmente tida como possível, assim como é possível produzir uma síntese tecnológica de artefatos, ou uma "síntese" química da matéria. Assim, para Newton, era muito natural dizer que tal como nas matemáticas, na Filosofia Natural, o método (distinto) da análise deve sempre preceder o método (distinto) da síntese, sendo a análise experimental e indutiva, [e a] síntese dedução do fenômeno a partir de princípios estabelecidos. (FERNANDES, 1985, p. 38)

À luz desses comentários, acreditamos que, com a descrição da sua versão dos métodos de análise e síntese, Newton pretendia: a) revelar, via análise, resultados generalizados pela indução, percorrendo o caminho proveniente dos efeitos observáveis para as causas particulares e destas para as causas gerais; e b) a partir das causas gerais, já declaradas como "princípios", via síntese, fornecer explicações adequadas para os fenômenos observados diretamente da natureza ou deduzidos de experimentos, fornecendo, finalmente, uma demonstração para as explicações de forma plausível. Contudo, Cohen teria algo mais a acrescentar:

O estudo cuidadoso, entretanto, mostra que o procedimento de Newton na Filosofia Natural experimental é exatamente o inverso da maneira como a 'análise' e a 'síntese' (ou a 'decomposição' e a 'composição’) eram tradicionalmente usadas em relação à matemática [...]. (COHEN, 2002, p. 167)

Por sugestão do próprio Cohen (2002), para entrarmos no núcleo do método de Newton teríamos que ter em mente o seguinte fato: a Filosofia Natural, para aquele pensador, 
constituía-se de uma mistura bem dosada entre as soluções matemáticas para os atos e propriedades naturais - físicas - e o estudo das causas físicas e metafísicas desses mesmos atos e propriedades naturais, nesta ordem. A maior comprovação da veracidade da hipótese de Cohen sobre qual teria sido de fato o método utilizado por Newton encontra-se nos escritos dos Princípios Matemáticos de Filosofia Natural.

Nessa obra, Newton iniciou seus escritos (os Livros I e II), questionando quais seriam as propriedades matemáticas de uma força, sem se preocupar com seu "tipo", suas causas ou seu modus operandi. Somente no Livro III, Newton mergulhou nas causas físicas e metafísicas dessas forças, elaborando quatro importantes regras e concluindo com um de seus mais proeminentes escritos metafísicos: o "Escólio Geral". A ligação profunda entre a matemática pura e a Física do movimento seria, de acordo com Cohen (2002), o traço mais marcante dessa suntuosa obra, no qual alguns aspectos da Filosofia Natural seriam reduzidos a princípios matemáticos, expostos ao leitor como exercícios de matemática e, finalmente, novamente aplicados a problemas físicos. Resumindo: para Cohen (2002), foi a matemática - e não a metafísica - que mostrou que leis do movimento matematicamente descritivas eram equivalentes a um conjunto de condições causais de forças e movimentos - o que não significa dizer que a metafísica não estivesse presente nas causas primeiras dos fenômenos que obedeciam estas leis. Sobre a ampla utilização da matemática nos Princípios Matemáticos de Filosofia Natural, Cohen fez uma importante observação relativa aos críticos e comentadores de Newton:

[...] embora essa mescla de matemática pura, derivada do movimento ou relacionada com ele, e problemas físicos de movimento possa têlo [a Newton] levado a obter resultados inauditos, de uma fecundidade espantosa, esse mesmo aspecto de seu trabalho tem causado enorme confusão entre seus críticos e intérpretes, desde aquela época. Em particular, eles nem sempre sabem quando Newton está falando no nível da matemática ou quando está no nível da física. Ou talvez tenham presumido que essa é uma distinção irrelevante e não se tenham dado ao trabalho de verificar se Newton, como matemático, pretendia em todos os pontos, nos Principia, ser entendido como físico. (COHEN, 2002, p. 176)

Finalizando, não acreditamos que mostrando o alcance da matemática para Newton em sua obra, Cohen tenha retirado a importância da metafísica associada à Filosofia Natural newtoniana. Pelo contrário: pensamos que o comentador posicionou esta metafísica de forma que, tanto para aqueles que afirmam que ela não existiu na obra de Newton, quanto para aqueles que, de maneira oposta, afirmam que ela existiria, todos, sem exceção, reconheçam seu verdadeiro lugar e importância para o desenvolvimento desta nova Física. Nas palavras de Cohen:

E foi a possibilidade de elaborar as conseqüências matemáticas das suposições relacionadas com possíveis condições físicas, sem ter que discutir a realidade física destas condições nas etapas mais iniciais, que marcou o estilo newtoniano. (COHEN, 2002, p. 171) 
Sapunaru, R. A.

\section{Referências}

BRACKENRIDGE, J. B. Newton's mature dynamics: a crooked path made straight. In: COHEN, B. I.; BUCHWALD, Z. J. (Eds.). Isaac Newton's Natural Philosophy. Cambridge: The MIT Press, 2001. p. 105-138.

COHEN, B. I. Newton: textos, antecedentes e comentários. Rio de Janeiro: EdUERJ/ Contraponto, 2002.

FERNANDES, C. S. L. Foundations of objective knowledge: the relations of Popper's theory of knowledge to that of Kant. Dordrecht: D. Reidel, 1985.

GREGORY, D. Nota de David Gregory. In: COHEN, B. I.; WESTFALL, S. R. (Orgs.). Newton: textos, antecedentes e comentários. Rio de Janeiro: EdUERJ/Contraponto, 2002. p. 150.

KOYRÈ, A. Études newtoniennes. Paris: Gallimard, 1985.

LAUDAN, L. Theories of scientific method from plato to mach. History of Science, EUA, v. 7, n. 219, p. 1-63, 1968.

NEWTON, I. Correspondências com Cotes e Oldenburg. In: COHEN, B. I.; WESTFALL, S. R. (Orgs.). Newton: textos, antecedentes e comentários. Rio de Janeiro: EdUERJ/ Contraponto, 2002. p. 155-158.

The principia: mathematical principles of natural philosophy. Trad. Bernard Cohen e Anne Whitman. Los Angeles: University of California Press, 1999.

SHAPIRO, E. A. Newton's experiments on difraction and the delayed publication of the Opticks. In: COHEN, B. I.; BUCHWALD, Z. J. (Eds.). Isaac Newton's Natural Philosophy. Cambridge: The MIT Press, 2001. p. 47-76.

SMITH, G. E. The methodology of the Principia. In: COHEN, B. I.; SMITH, G. E. (Eds.). The Cambridge Companion to Newton. Cambridge: Cambridge University Press, 2002. p. 138-173.

. The Newtonian Style in Book II of The Principia. In: COHEN, B. I.;

BUCHWALD, Z. J. (Eds.). Isaac Newton's Natural Philosophy. Cambridge: The MIT Press, 2001. p. 249-298.

Artigo recebido em março de 2007 e aceito em outubro de 2007. 